\title{
A cross-country comparison of malaria policy as a premise for contextualized appropriation of foreign aid in global health
}

Tomas Jezek ${ }^{1^{*}}$ and Oluwaseun Adebayo Bamodu $2,3,4$

\begin{abstract}
Background: Foreign aid continues to play an essential role in health sector development in low-resource countries, particularly in terms of providing a vital portion of their health expenditures. However, the relationship between foreign aid allocation and malaria policy formulation and/or implementation among state aid recipients remains unknown.

Methods: Publicly available data were collected with the country as observational unit to set up the conceptual framework. The quality and strength of relationships between socioeconomic, environmental and institutional parameters were estimated by Pearson and polychoric correlations. A correlation matrix was explored by factor analysis.

Results: The first policy index captured policy variation related to malaria burden and development assistance. Funding per capita from all international agencies was correlated with malaria burden, whereas governmental funding for national malaria programmes per capita was not. The second policy index captured variation beyond malaria endemicity and country size. Variation was found to be related to international country risk instruments and funding from the United States Agency for International Development President's Malaria Initiative.

Conclusions: Not all agencies involved in malaria policy allocate assistance in alignment with the gross domestic product and malaria burden. While the country size does not negatively impact malaria burden, it does account for greater development assistance per capita from selected international agencies. Novel policy indexes describe complex relationships between malaria policy, international foreign aid and socioeconomic parameters. Small countries have distinct environmental and sociopolitical properties.
\end{abstract}

Keywords: Environmental health, Public health, Global health, Healthcare economics and organizations, Health policy, International agencies, Malaria

\section{Background}

Studies on economic development have found strong associations between geography and gross domestic product (GDP) per capita [1]. Coastal economies are favourably located for foreign trade and have generally higher GDP than landlocked economies. Coastlines and

\footnotetext{
*Correspondence: tomas.jezek@volny.cz

1 Department of Preventive Medicine, Faculty of Medicine, Masaryk University, Brno, Czech Republic

Full list of author information is available at the end of the article
}

areas connected to the coast by navigable waterways are more densely populated than the hinterlands. Most tropical countries are economically poor. Several studies suggest that economic development is fundamentally determined by the quality of institutions [2].

While the first foreign aid can be traced as far back as the 19th century, the flow of foreign aid globally has steadily increased since the Second World War. While the process of establishing independence by colonies may have contributed to this increase, a methodical shift from internal (within one administrative entity)

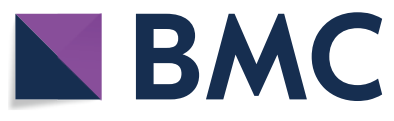

(c) The Author(s) 2021. Open Access This article is licensed under a Creative Commons Attribution 4.0 International License, which permits use, sharing, adaptation, distribution and reproduction in any medium or format, as long as you give appropriate credit to the original author(s) and the source, provide a link to the Creative Commons licence, and indicate if changes were made. The images or other third party material in this article are included in the article's Creative Commons licence, unless indicated otherwise in a credit line to the material. If material is not included in the article's Creative Commons licence and your intended use is not permitted by statutory regulation or exceeds the permitted use, you will need to obtain permission directly from the copyright holder. To view a copy of this licence, visit http://creativecommons.org/licenses/by/4.0/. The Creative Commons Public Domain Dedication waiver (http://creativeco mmons.org/publicdomain/zero/1.0/) applies to the data made available in this article, unless otherwise stated in a credit line to the data. 
to foreign transfer is also considered to be a significant contributory factor. Studies on the economic development of former colonies highlight the substantial impact of institutional development [2]. Howbeit, some studies have suggested that the historical phenomenon of colonial rule has insidiously evolved into indirect economic control exercised by international organizations, bilateral donors and (semi-)private investors, forming neocolonial practices [3].

Many emerging or newly emerged states are strategically positioned and economically aligned, having joined international organizations, regardless of their geographical or population size, thus amplifying the political, social and economic clout of such small countries beyond what the population size alone would suggest. Analyses of foreign aid disbursement in the 1970s reveal that small countries received more foreign aid per capita than their larger counterparts. This so-called 'small country effect' has been attributed to the perceived and/or actual economic openness of small countries, which is probably linked to an existent need for more aid to finance their imports [4]. Other explanations include a major role for economic and political properties which small countries have taken from their history. Geographical area is not the sole parameter used in defining small states. According to the World Bank, countries with a population of 1.5 million or less, or membership in the Small States Forum, are considered as small [5]. Other definitions have hinged on aggregated indicators [6], factor analysis [7] or cluster analysis [8].

In the historical context, the relationship between socioeconomic parameters and health contributed to the emergence of epidemiology as a standalone scientific discipline. This in itself has been the undertone in several studies that have depicted colonial history as a direct sociopolitical determinant of health [9], in addition to accrued evidence of a similar impact by the history of socialist systems, or conflicts and wars. The acclaimed elimination of malaria from wealthier countries in the first half of the 20th century was a result of both socioeconomic development and intensive antimalarial interventions [10]. However, up to the present day, malaria accounts for one of the highest disease burdens in global or public health, even when prevention and treatment of malaria remain largely cost-effective public health interventions. The return on investments in malaria prevention and treatment could be as high as 40 -fold, compared with inaction [11], thus underlying the suggested strong association between a country's malaria burden and its economic development [1]. This informs the need to include policies for malaria control in government poverty reduction agenda [12]. Foreign aid for malaria control is largely provided by international organizations such as the Global Fund to Fight AIDS, Tuberculosis and Malaria (Global Fund), the World Bank or the United Nations Children's Fund (UNICEF). The United States Agency for International Development (USAID) monitors the stability, recovery and democratic reforms in state recipients of foreign aid using the International Country Risk Guide (ICRG) index for political, economic and financial risk rating [13]. A good understanding and informed re-evaluation of current allocation policy are critical for improving the effectiveness of foreign aid.

In most cases, health policy analyses performed 'outof-state' tend to omit or ignore the political implications/ ramifications of the public health agenda of interest. Since many of the countries affected by malaria have a colonial history, malaria is also subject to developmental policies, and policies are usually shaped through complex interactions of key stakeholders. However, the relationships between the environment, institutions, malaria as a disease entity and health policy have rarely been explored. Little is known about the decision-making process for selecting and altering national malaria intervention policies. Given that national health policy on malaria is defined at the country level, we posit that cross-country comparisons could provide some needed insight into such health policy processes. While major decisive factors are often difficult to identify, it is highly probable that they vary between countries. This cannot be ascertained without robust analytical frameworks, which are currently lacking [14]. Thus, there is a need for for the present study, which has the aim to identify and demystify key parameters that affect decision-making and health policy implementation, with particular reference to malaria policies. The results reported herein are intended to assist decision-makers in the informed implementation and critical evaluation of public health interventions for malaria control.

\section{Methods \\ Study model and working hypotheses}

This study was based on a statistical analysis of the hypothesis that environmental, socioeconomic and institutional parameters affect a country's malaria intervention policy. Parameters reported at the country level that could be related to the malaria policy were identified from the literature review. The term 'country' herein is as defined by the International Organization for Standardization [15].

To aid validation of the hypotheses, we constructed a conceptual framework with parameters clustered into socioeconomic, environmental and institutional groups (Fig. 1). Socioeconomic parameters included the GDP, national budget, economic stability and the level of urbanization. Environmental parameters are related to 


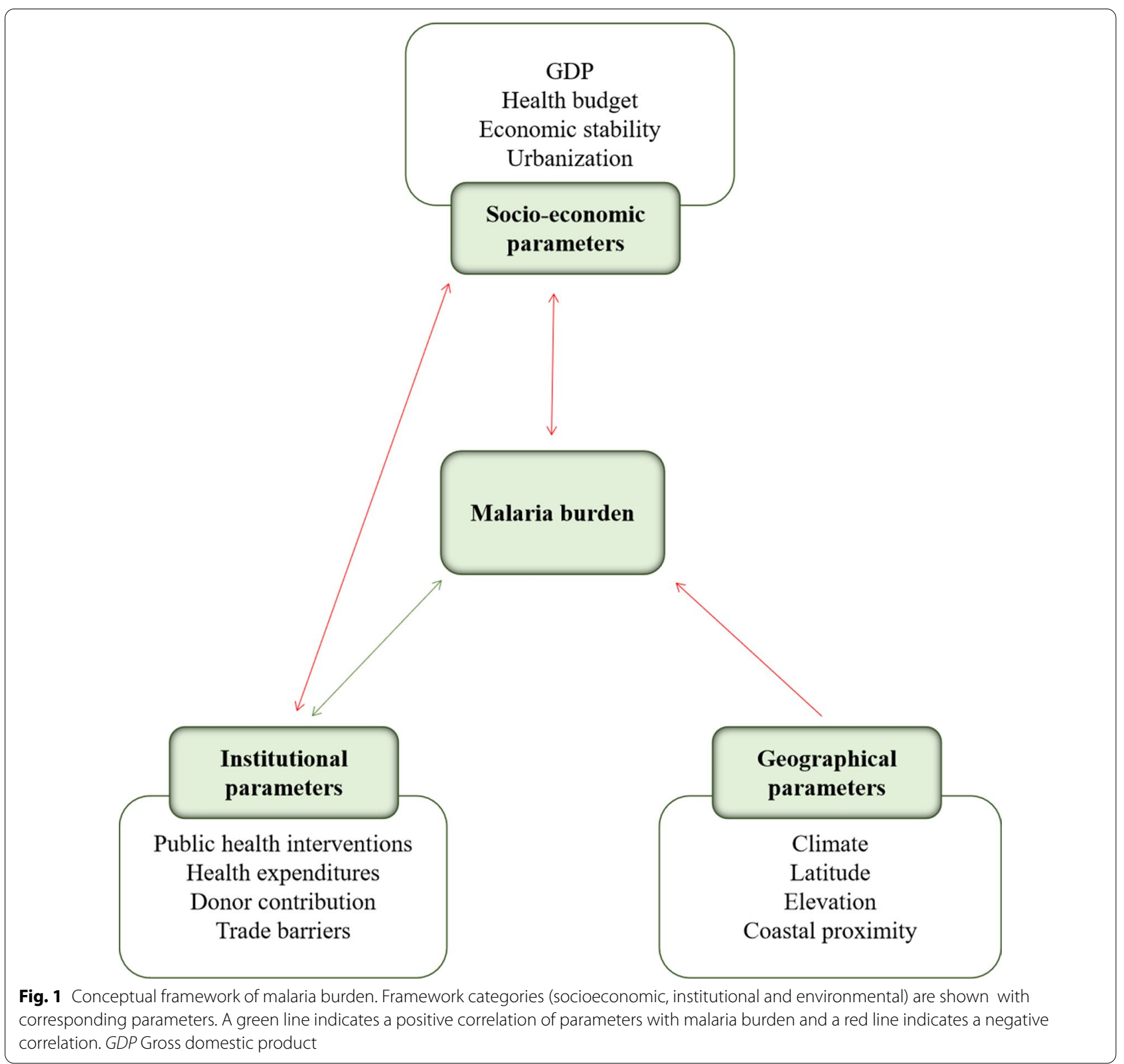

geographic conditions such as temperature, latitude, elevation above sea level and coastal and island locations. Institutional parameters include government policies, trade barriers, health services and policies, educational programmes, agricultural incentives and infrastructure projects [16].

National malaria intervention policy and strategy adoption vary between countries. This variability is related to characteristics that are not known or not directly observable. Factor analysis allows us to identify underlying relationships as it creates new factors with detectable relationships to latent parameters. Based on these factors we are able to distinguish countries based on the health policies they have adopted.

\section{Variables}

Explanatory variables were derived from the study hypothesis and taken at the country level. Where per capita data were not available, corresponding values were generated using the total population of the country. The latitude component of the country centroid was measured in absolute terms. Total health spending refers to average expenditures on health per person, expressed in international dollars using purchasing 
power parity (PPP). Most variables were taken for the last available year, 2016. Data for the ICRG index were extracted from previously published reports [1] in order to facilitate comparisons with our results.

Since the definition of a small country is not standardized, the status of small country was ascribed only if this country fulfilled all of the World Bank criteria with or without membership in the Small States Forum (SSF). Countries included in the SSF are listed in Additional file 1. The binary variable was set as 1 for countries fulfilling the 'small country' criteria, and as 0 for the other countries. The binary variable for being landlocked was set as 1 for countries with no access to the sea, and 0 for the other countries.

Openness, which is a measure of a country's macroeconomic policies that interfere with foreign trade, was measured by the proportion of years from 1965 to 1990 that a country was open to trade [17].

The ICRG is a widely used indicator of institutional quality. The ICRG rating consists of five indicators adjudged to be highly relevant to the security of private property and the enforceability of contracts, such as the frequency of contract repudiation, the risk of expropriation, corruption in the government, a tradition of law and order and bureaucratic quality [18]. Countries are scored on a scale of 0 to 10 according to perceived institutional quality, with a higher score indicating a lower risk.

The concept of the Human Development Index (HDI) was conceived to measure social development [19]. The HDI is based on the average of three indicators, namely, life expectancy at birth, years of schooling for adults and expected years of schooling for children, as well as (log) GDP per capita.

The population at risk of malaria transmission was defined as the population living in areas where malaria transmission is reportedly to be endemic. The malaria incidence rate was defined as the number of malaria cases per 1000 people in the risk population per year. The rate of malaria incidence reflects the burden of malaria. The binary variable for malaria transmission was defined based on the malaria incidence, with 0 for countries with null incidence (absent) and 1 for countries with an incidence $>0$ (present). The national intervention policy and strategy adoption for malaria were transformed to dichotomous variables. The binary variable for health policy was set as 1 (policy present) or 0 (policy absent). In the absence of general recommendations for the use of intermittent preventive treatment in pregnancy (IPTp) outside of Africa [20], values for non-African countries were imputed as 0 (absent). Missing values were imputed as 0 (absent).

\section{Data collection}

We tested our hypotheses using the dataset in which countries were the observational units. Parameters at the country level were assembled into a database. The data were collected from public sources, including the WHO, World Bank and the Center for International Development (Additional file 2). The data quality control of the primary sources was assumed to be sufficient to prevent missing data or selection bias.

\section{Data analysis}

Potential outliers were identified. Quantitative variables with skewed distributions were transformed using the common logarithm $\left(\log _{10}\right)$ or the square root, as statistically appropriate. Variables $\leq 0$ were rescaled prior to transformation to avoid data loss.

The strength of the relationships between continuous variables was estimated by the Pearson correlation coefficient $(r)$, and magnitudes were classed as strong, moderate and weak based on $r$ thresholds of $0.70,0.50$ and 0.20 in absolute terms, respectively. The strength of the relationships between categorical variables was estimated by the polychoric correlation coefficient. The tetrachoric variant of the polychoric correlation was used to estimate the correlation between two dichotomous variables. Tetrachoric correlation uses the $2 \times 2$ contingency table as a double dichotomization of a bivariate standard normal distribution [21]. Tetrachoric correlation coefficients were added to the correlation matrix and explored by factor analysis. The eigenvalue $(\kappa)$ of factors extracted for further analysis was set as 1 [22]. The resulting factors (1-6) constituted new policy scores (1-6, respectively).

Continuous and binary variables were compared using two sample $t$-tests. Statistical significance was determined using a two-sided significance level of $\alpha=0.05$. Predictors of malaria outcome were analysed by the multiple linear regression with the following model:

$$
\begin{aligned}
Y(\text { malaria outcome })= & \beta 0+\beta 1 X 1+\beta 2 X 2 \\
& +\gamma(X 1 * X 2)+\varepsilon
\end{aligned}
$$

A similar probit model was used for the dependent binary variable of malaria transmission. Models were extended to include interaction terms and possible confounding factors to avoid multicollinearity. The goodness-of-model fit was measured by the $R^{2}$ or pseudo $R^{2}$ statistic, as appropriate.

Consistency checks and statistical analyses were conducted using Stata 14 software (StataCorp 2015. Statistical Statistical Software: Release 14. StataCorp LP, College Station, TX, United States of America). 


\section{Results}

\section{Descriptive statistics}

The majority of variables were found to have skewed distribution and were transformed by either taking the logarithm or square root. The basic variable characteristics are described in terms of means and standard deviations for continuous variables (Table 1) or as counts and proportions for categorical variables (Table 2 ).

\section{Analysis of international funding}

Funding per capita from the Global Fund $(r=0.45$, $p<0.01$ ), USAID President's Malaria Initiative (PMI USAID) $(r=0.49, p<0.01)$, United Kingdom of Great Britain and Northern Ireland (hereafter, United Kingdom) government $(r=0.25, p<0.05)$ and UNICEF $(r=0.35, \quad p<0.01)$ was positively correlated with malaria burden. Funding per capita was found to be negatively correlated with the GDP (Global Fund: $r=-0.50, p<0.01$; UNICEF: $r=-0.57, p<0.01$; PMI USAID: $=-0.49, p<0.01$ ) (Additional file 3).

The Global Fund funding per capita exhibited statistically significant but weak negative correlation with land area $(r=-0.33 ; p<0.01)$ and population size $(r=-0.37$; $p<0.01$ ) (Additional file 3). Although statistically significant, Government National Malaria Programme (NMP) funding per capita showed a moderately negative correlation with the land area $(r=-0.46 ; p<0.01)$ and with population size $(r=-0.53 ; p<0.01)$, with Sao Tome and Principe being an outlier. The PMI USAID funding per capita was also found to exhibit significant negative correlation with latitude $(r=-0.24 ; p<0.05)$. Moreover, consistent with speculations that the official language of recipient countries plays a role in the source and ease of securing global health funding, we found that there was significantly strong positive correlation between PMI USAID $(r=0.26, p<0.05)$, United Kingdom funding

Table 1 Descriptive statistics of continuous variables

\begin{tabular}{|c|c|c|c|c|c|c|}
\hline Variable & Units & $N$ & Mean & SD & Minimum & Maximum \\
\hline Land area & $\log$ of km² & 215 & 4.72 & 1.31 & 0.30 & 7.22 \\
\hline Latitude of country centroid & Absolute degree & 164 & 27.35 & 17.78 & 0.42 & 74.70 \\
\hline Elevation above sea level & Mean metres & 164 & 626.92 & 560.98 & 9.17 & 3185.92 \\
\hline Population size & $\log$ & 215 & 6.59 & 1.06 & 4.05 & 9.13 \\
\hline Population density & $\log$ & 195 & 1.9 & 0.62 & 0.29 & 4.41 \\
\hline Urban population & Proportion & 215 & 0.6 & 0.24 & 0.12 & 1.00 \\
\hline Population within $100 \mathrm{~km}$ of coast & Proportion & 164 & 0.43 & 0.36 & 0.00 & 1.00 \\
\hline GDP per capita PPP & Log of US\$ & 192 & 4.07 & 0.5 & 2.9 & 5.06 \\
\hline Total GDP PPP & Log of millions US\$ & 192 & 10.79 & 1.04 & 7.62 & 13.28 \\
\hline Total health expenditure per capita PPP & Log of international dollars & 185 & 2.83 & 0.57 & 1.47 & 3.99 \\
\hline Government health to total government expenditure & Proportion & 186 & 3.56 & 2.34 & 0.37 & 13.06 \\
\hline Official development assistance received per capita & Current US\$ & 139 & 124.24 & 318.11 & -2.34 & 3034.15 \\
\hline Openness (Sachs\&Warner) & - & 139 & 0.25 & 0.40 & 0.00 & 1.00 \\
\hline ICRG index & - & 98 & 5.68 & 2.26 & 2.27 & 9.98 \\
\hline $\mathrm{HDI}$ & - & 188 & 0.69 & 0.15 & 0.35 & 0.94 \\
\hline Malaria incidence & Per 1000 population at risk & 105 & 96.03 & 129.49 & 0.05 & 460.90 \\
\hline Plasmodium vivax species & Proportion & 105 & 0.27 & 0.37 & 0.00 & 1.00 \\
\hline Global Fund funding for malaria control per capita ${ }^{a}$ & US\$ & 90 & 0.88 & 1.82 & -0.07 & 14.85 \\
\hline PMI USAID funding for malaria control per capita ${ }^{a}$ & US\$ & 90 & 0.27 & 0.55 & 0.00 & 3.10 \\
\hline World Bank funding for malaria control per capita ${ }^{a}$ & US\$ & 91 & 0.01 & 0.03 & -0.01 & 0.20 \\
\hline $\begin{array}{l}\text { United Kingdom development funding for malaria control } \\
\text { per capita }{ }^{a}\end{array}$ & US\$ & 90 & 0.04 & 0.20 & 0.00 & 1.29 \\
\hline Government funding for malaria control per capita ${ }^{a}$ & US\$ & 70 & 0.80 & 2.98 & 0.00 & 24.89 \\
\hline UNICEF funding for malaria control per capita ${ }^{a}$ & US\$ & 61 & 0.03 & 0.13 & 0.00 & 1.04 \\
\hline Policy score 1 & - & 93 & 0.08 & 0.40 & -0.69 & 0.82 \\
\hline Policy score 2 & - & 93 & 0.73 & 0.39 & -0.47 & 1.44 \\
\hline Policy score 3 & - & 93 & -0.18 & 0.40 & -0.87 & 0.92 \\
\hline Policy score 4 & - & 93 & 1.02 & 0.39 & -0.05 & 1.84 \\
\hline
\end{tabular}

GDP Gross domestic product, Global Fund Global Fund to Fight AIDS, Tuberculosis and Malaria, HDI Human Development Index NMCP National Malaria Control Programme, ICRG International Country Risk Guide, PMI United States President's Malaria Initiative, PPP purchasing power parity, SD standard deviation, UNICEF United Nations Children's Fund, USAID United States Agency for International Development, log common logarithm

${ }^{\text {a }}$ Funding for malaria control (except for UNICEF) as reported by donors 
Table 2 Descriptive statistics of categorical variables

\begin{tabular}{|c|c|c|}
\hline Variable & $N$ & $\begin{array}{l}\text { Proportion } \\
\text { of countries }\end{array}$ \\
\hline Small country dummy & 215 & 0.35 \\
\hline Landlocked country dummy & 149 & 0.23 \\
\hline Island dummy & 96 & 0.64 \\
\hline English language dummy & 215 & 0.42 \\
\hline ITNs/LLINs are distributed free of charge & 93 & 0.89 \\
\hline ITNs/LLINs are distributed to all age groups & 93 & 0.75 \\
\hline ITNs/LLINs are distributed through mass campaigns to all age groups & 93 & 0.75 \\
\hline IRS is recommended by malaria control programme & 93 & 0.90 \\
\hline DDT is used for IRS & 93 & 0.10 \\
\hline IPTp is used to prevent malaria during pregnancy & 93 & 0.40 \\
\hline Seasonal malaria chemoprevention (SMC or IPTC) is used & 93 & 0.11 \\
\hline Patients of all ages should get diagnostic test & 93 & 0.99 \\
\hline Malaria diagnosis is free of charge in the public sector & 93 & 0.86 \\
\hline RDTs are used at community level & 93 & 0.56 \\
\hline G6PD test is recommended before treatment with primaquine & 93 & 0.19 \\
\hline ACT for treatment of Plasmodium falciparum & 93 & 0.99 \\
\hline Pre-referral treatment with quinine or artemether IM or artesunate suppositories & 93 & 0.59 \\
\hline Single dose of primaquine is used as gametocidal medicine for $P$. falciparum & 93 & 0.47 \\
\hline Primaquine is used for radical treatment of Plasmodium vivax cases & 93 & 0.57 \\
\hline Directly observed treatment with primaquine is undertaken & 93 & 0.29 \\
\hline
\end{tabular}

ACT Artemisinin-based combination therapy, DDT dichloro-diphenyl-trichloroethane, G6PD glucose-6-phosphate dehydrogenase, IM intramuscular, IPTC intermittent preventive treatment in children, IPTp intermittent preventive treatment in pregnancy, IRS indoor residual spraying, ITN insecticide-treated mosquito net, LLIN longlasting insecticidal net, $R D T$ rapid diagnostic test, SMC seasonal malaria chemoprevention

Table 3 Logistic regression model of any malaria transmission

\begin{tabular}{ll}
\hline Independent variables (unit) & $\begin{array}{l}\text { Any malaria transmission (95\% } \\
\text { Cl) }\end{array}$ \\
\hline Land area (log km²) & $1.531(0.688-2.374)^{* *}$ \\
Latitude of country centroid (abs) & $-0.151(-0.210 \text { to } 0.091)^{* *}$ \\
GDP per capita (log US\$) & $-3.099(-4.514 \text { to }-1.685)^{* *}$ \\
Pseudo $R^{2}$ & 0.68 \\
$N$ & 157
\end{tabular}

Dependent variable: malaria transmission. A country is considered as having malaria transmission if malaria incidence is $>0$

Cl Confidence interval

${ }^{*} p<0.05 ;{ }^{* *} p<0.01$

$(r=0.33, p<0.01)$ and the English-speaking status of recipient countries (Tables 3,4$)$.

\section{Analysis of country size}

Small countries did not seem to differ significantly from large countries in terms of their malaria burden [diff = 0.28 (95\% confidence interval: -2.86 to 3.42 ); $P=0.85$ ] (data not shown). Being a small country showed a strong positive correlation with being an island, a moderate positive correlation with official development assistance received per capita, including Global Fund and government NMP funding for malaria control per capita, and a weak positive correlation with population density. Conversely, being a small country exhibited a strong negative correlation with population size and land area, but a weak negative correlation with PMI USAID funding per capita (Additional file 3).

\section{Malaria intervention policies and strategy adoption}

Binary indicators for malaria national intervention policies and strategy adoption (Table 5) were used for the factor analysis. From the analysis, factors 1-6, which had eigenvalues of $>1$, accounted for $89 \%$ of the total variation. Factors 1 and 2 were not found to be clustered and their highest loadings exceeded the statistically strong absolute value of 0.70 . Factors $1-4$ had $\geq 3$ variables with loadings above (absolute) 0.50 . The relationships between the factors, malaria burden, and the social, economic and environmental variables are shown in Fig. 2 and listed in Additional file 3.

\section{Policy scores}

As shown in Additional file 3, policy score 1 showed a moderate positive correlation with the HDI $(r=0.69$; 
Table 4 Multiple linear regression model of malaria burden

\begin{tabular}{lll}
\hline Independent variables (unit) & Malaria burden (log) (95\% Cl) & $\begin{array}{l}\text { Malaria burden (log) with } \\
\text { small country dummy (95\% } \\
\text { Cl) }\end{array}$ \\
\hline Population density (log) & & $-0.351(-0.669 \text { to }-0.007)^{*}$ \\
Latitude of country centroid (abs) & $-0.349(-0.669 \text { to }-0.030)^{*}$ & $-0.067(-0.080 \text { to }-0.051)^{* *}$ \\
Elevation (mean m a.s.l., square root) & $-0.067(-0.081 \text { to }-0.052)^{* *}$ & $0.022(-0.040 \text { to }-0.004)^{*}$ \\
GDP per capita (log US\$) & $-0.022(-0.040 \text { to }-0.004)^{*}$ & $-1.497(-1.857 \text { to }-1.137)^{* *}$ \\
Small country (dummy) & $-1.498(-1.854 \text { to }-1.142)^{* *}$ & $0.013(-0.622$ to 0.595$)$ \\
$R^{2}$ & - & 0.694 \\
$N$ & 0.698 & 91
\end{tabular}

Dependent variable: malaria burden

${ }^{*} p<0.05 ;{ }^{* *} p<0.01$

Table 5 Malaria national intervention policy and factor loadings

\begin{tabular}{|c|c|c|c|c|c|c|}
\hline Malaria national intervention policy and strategy adoption & Factor 1 & Factor 2 & Factor 3 & Factor 4 & Factor 5 & Factor 6 \\
\hline ITNs/LLINs are distributed free of charge & -0.31 & -0.22 & -0.59 & 0.56 & 0.32 & 0.06 \\
\hline ITNs/LLINs are distributed to all age groups & 0.03 & 0.58 & -0.11 & 0.66 & 0.01 & -0.40 \\
\hline ITNs/LLINs distributed through mass campaigns to all age groups & -0.47 & 0.41 & -0.5 & 0.18 & 0.29 & -0.31 \\
\hline IRS is recommended by malaria control programme & -0.16 & 0.68 & 0.11 & -0.47 & 0.19 & -0.34 \\
\hline DDT is used for IRS & -0.03 & 0.57 & 0.47 & -0.04 & 0.61 & 0.25 \\
\hline IPTp is used to prevent malaria during pregnancy & -0.66 & 0.05 & 0.6 & 0.38 & -0.15 & 0.06 \\
\hline Seasonal malaria chemoprevention (SMC or IPTC) & -0.67 & -0.08 & 0.65 & 0.26 & -0.02 & -0.02 \\
\hline Patients of all ages should get diagnostic test & 0.55 & 0.01 & 0.66 & 0.5 & -0.05 & 0.03 \\
\hline Malaria diagnosis is free of charge in the public sector & 0.67 & 0.21 & 0.05 & 0.33 & 0.43 & 0.34 \\
\hline RDTs are used at community level & -0.41 & 0.35 & -0.43 & -0.11 & -0.07 & 0.61 \\
\hline G6PD test is recommended before treatment with primaquine & 0.40 & 0.25 & -0.31 & 0.49 & -0.54 & 0.11 \\
\hline ACT for treatment of Plasmodium falciparum & -0.40 & 0.82 & 0.08 & -0.08 & -0.37 & 0.02 \\
\hline Pre-referral treatment with quinine or artemether IM or artesunate supp & -0.70 & 0.32 & -0.19 & 0.15 & -0.12 & 0.21 \\
\hline $\begin{array}{l}\text { Single dose of primaquine is used as gametocidal medicine for Plasmo- } \\
\text { dium falciparum }\end{array}$ & 0.68 & 0.53 & -0.01 & -0.05 & 0.02 & 0.1 \\
\hline Primaquine is used for radical treatment of Plasmodium vivax & 0.91 & 0.01 & -0.17 & 0.11 & 0.05 & -0.13 \\
\hline Directly observed treatment with primaquine is undertaken & 0.66 & 0.43 & 0.10 & -0.22 & -0.29 & 0.04 \\
\hline
\end{tabular}

Factor loadings: factors 1-6

$p<0.01)$, GDP per capita $(r=0.66 ; p<0.01)$ and total health expenditure per capita $(r=0.66 ; p<0.01)$, a mild positive correlation with being an island $(r=0.49$; $p<0.01)$, urban population share $(r=0.46 ; p<0.01)$, the latitude $(r=0.41 ; p<0.01)$, population within 100 $\mathrm{km}$ of the coast $(r=0.38 ; p<0.01)$, the proportion of government health expenditure to total government expenditure $(r=0.36 ; p<0.01)$ and economic openness $(r=0.23 ; p<0.05)$. In contrast, although statistically significant, policy score 1 exhibited strong negative correlation with the malaria burden $(r=-0.78 ; p<0.01)$, a moderate negative correlation with PMI USAID funding $(r=-0.57 ; p<0.01)$ and weak negative correlation with Global Fund aid $(r=-0.38 ; p<0.01)$, World
Bank aid $(r=-0.20 ; p<0.05)$, United Kingdom government funding $(r=-0.31 ; p<0.01)$, UNICEF funding $(r=-0.36 ; p<0.01)$ per capita and being a landlocked country $(r=-0.23 ; p<0.05)$. Howbeit, policy score 1 was not significantly related to government NMP funding per capita or being a small country.

As depicted in Fig. 3, policy score 2 showed a weakly negative correlation with the ICRG index $(r=-0.26$; $p<0.05)$, PMI USAID funding per capita $(r=0.21$; $p<0.05)$ and being a small country $(r=-0.27 ; p<0.01)$. Policy score 2 was not significantly correlated with GDP per capita or the malaria burden.

Policy score 3 exhibited a weak negative correlation with the proportion of Plasmodium vivax $(r=-0.27$; 

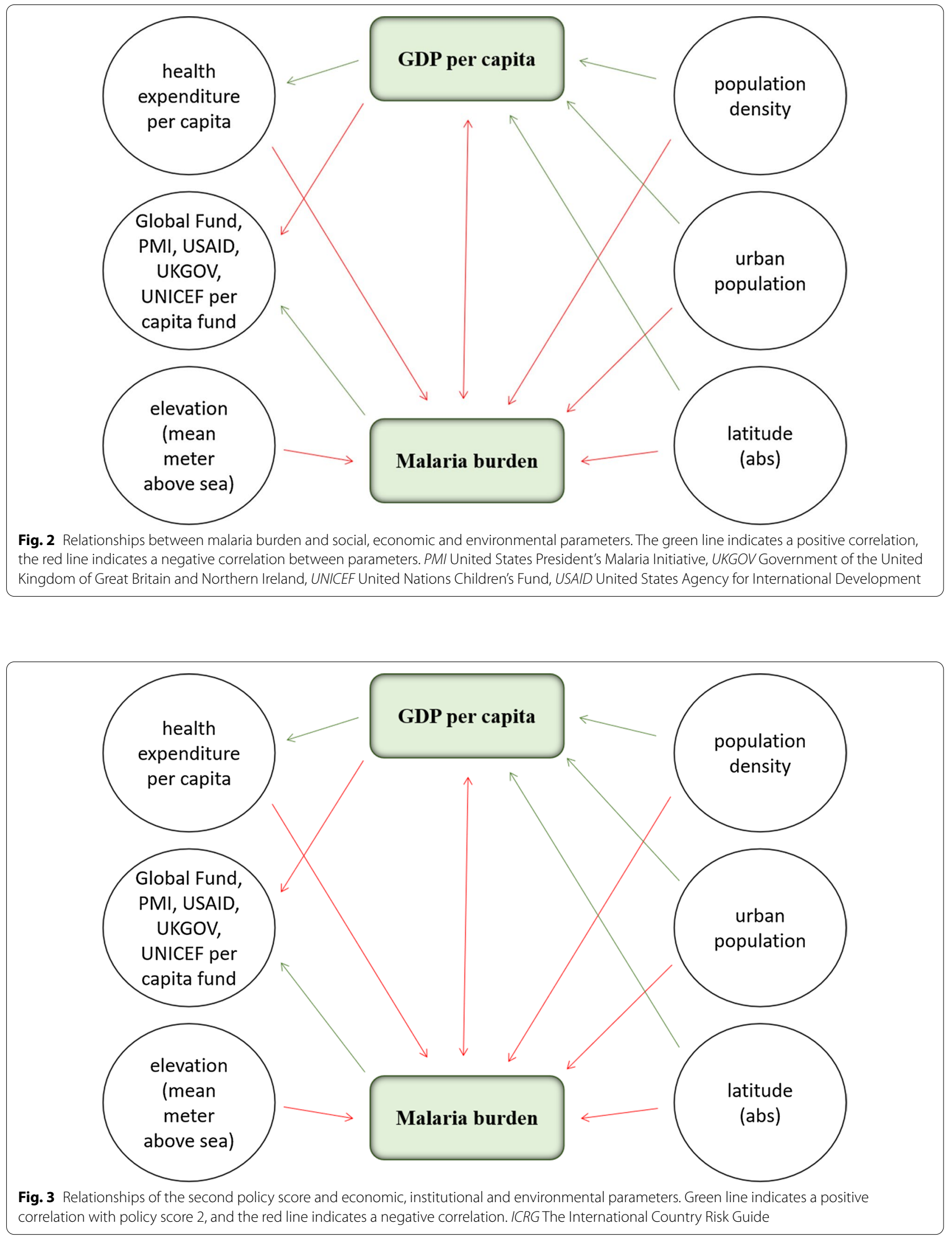
$p<0.01)$ and elevation above sea level $(r=-0.24$; $p<0.05)$. Since the prevalence of Plasmodium falciparum outside Africa is generally below 5\%, policy score 3 could also be considered as representing malaria policy outside Africa. Policy score 4 was statistically significant and weakly correlated with openness $(r=0.28 ; p<0.05)$ and PMI USAID funding per capita $(r=0.21 ; p<0.05)$.

\section{Discussion}

The primary objective of the study was to identify key parameter(s) that influence the allocation of funding for malaria control and the implementation of national malaria intervention policies. The novel policy indexes presented herein reflect not only malaria endemicity, but also 'epi-endemicity' parameters.

\section{International funding}

Hitherto, the commitment of international agencies has determined the success of malaria control programmes, with such international aid accounting for approximately $68 \%$ of global funding for malaria. The largest share of malaria funding ( $40 \%$ of total funding) is provided by The Global Fund, followed by the PMI USAID (26\%), the government of the United Kingdom (7\%) and the World Bank (3\%). Both the government of the United Kingdom and the PMI USAID also contribute to the Global Fund. In the last decade, multinational organizations have steadily increased their global health agenda support, such that their contribution is purportedly higher than those of organizations that were specifically established to promote global health agenda, such as the WHO.

The outcomes presented here suggest that funding for malaria control per capita is inconsistently distributed depending on the funding provider. The populace of smaller countries and countries with smaller populations benefit disproportionally from malaria control funding. Only PMI USAID funding is related to the institutional quality of the recipient country.

\section{Policy indexes}

The first policy index describes the endemicity of malaria. The second policy index indicates economic and institutional conditions in 93 countries and represents the variation in national malaria intervention policy that is not nor can be explained by malaria endemicity (Additional file 4). Since the second policy score is related to the size of the country but not to malaria or GDP, this score explains novel components of the small country bias. The quality of institutions is adversely affected by corruption, thus reducing corruption improves the institutional quality and often translates into more efficient healthcare systems [23]. Corruption is negatively correlated with public spending on education and health, and even with total health expenditure per capita [24]. Improving the quality of national institutions seems to increase the average personal spending on health [25].

\section{Small countries}

High costs of public service, telecommunication and transportation impede the delivery of healthcare, educational and infrastructure services in small countries. Many governments are implementing health system reforms in order to improve health services and health financing. International agencies support these reforms through various development policies. Our results do not support the claim that small countries are disadvantaged in the allocation of GDP per capita or that they face a higher malaria burden. Nevertheless, small countries receive more foreign aid or international development assistance per capita. This may be attributed, in part, to the high cost of delivering this development assistance due to poor geographic conditions. It is also possible that different allocation criteria are employed for these small countries. Interestingly, although, many small countries experience the emergence and re-emergence of vectorborne diseases [26], according to our data, malaria is more likely to increase in larger countries than in their smaller counterparts.

\section{Limitations}

The strength of any data analysis depends on the accuracy of the data. The specific ecosystem of malaria research utilizes data from many sources of varying quality. Nevertheless, we have used the same data sources as used by the WHO, so we assume that the data quality is sufficient to address our questions. Most variables were derived from public datasets from 2016; however some data generated by private organizations had restricted access, being freely available only for selected past years.

\section{Conclusions}

The present study proffers novel policy indexes that encapsulate the critical but complex relationships between foreign aid and the socioeconomic parameters of recipient countries. The second policy index is independent of malaria endemicity and provides novel insight into malaria policy formulation and/or implementation.

Our findings support the indispensability of fiscal transparency and the data-driven approach, as well as reveal that not all involved agencies allocate funding for malaria control based on GDP or malaria burden. These results provide a basis for and encourage further studies on the interplay between the allocation of malaria control funds and implementation of national malaria intervention policies. Having these results from the 
country level could contribute to a better allocation of malaria funding.

The small country effect is deeply entrenched in international developmental policies following claims of state economic disparity and small country disadvantages. However, our study did not confirm disadvantages in the social and economic resources of small countries if parameters are analysed per capita. The country size bias does account for greater development assistance per capita from selected international agencies. Awareness of all these factors highlights the need for better adjustment of aid allocation to the distinct needs of small countries.

\section{Abbreviations}

ACT: Artemisinin-based combination therapy; DDT: Dichloro-diphenyl-trichloroethane; G6PD: Glucose-6-phosphate dehydrogenase; GDP: Gross domestic product; Global Fund: Global Fund to Fight AIDS, Tuberculosis and Malaria; HDI: Human Development Index; ICRG: International Country Risk Guide; IM: Intramuscular; IPTC: Intermittent preventive treatment in children; IPTp: Intermittent preventive treatment in pregnancy; IRS: Indoor residual spraying; ITN: Insecticide-treated mosquito net; LLIN: Long-lasting insecticidal net; log: Common logarithm; NMP: National Malaria Programme; PPP: Purchasing power parity; PMI: The US President's Malaria Initiative; RDT: Rapid diagnostic test; SMC: Seasonal malaria chemoprevention; USAID: United States Agency for International Development; UNICEF: United Nations Children's Fund; WHO: World Health Organization.

\section{Supplementary Information}

The online version contains supplementary material available at https://doi. org/10.1186/s12961-021-00700-6.

Additional file 1. Small countries and dependent territories.

Additional file 2. Data sources.

Additional file 3. Correlation matrix of policy scores, malaria, social, economic and environmental parameters.

Additional file 4. Second policy score.

\section{Acknowledgements}

The authors are grateful to the reviewers of this paper for their helpful comments.

\section{Authors' contributions}

TJ: Study conception and design, collection and assembly of data. TJ, OAB: Data analysis and interpretation, figure design, manuscript writing. Both authors read and approved the final manuscript.

\section{Funding}

Not applicable.

\section{Availability of data and materials}

The datasets used and/or analysed during the current study are available from the corresponding author on reasonable request.

\section{Declarations}

Ethics approval and consent to participate Not applicable.
Consent for publication

Not applicable.

\section{Competing interests}

The authors declare that they have no competing interests.

\section{Author details}

${ }^{1}$ Department of Preventive Medicine, Faculty of Medicine, Masaryk University, Brno, Czech Republic. ${ }^{2}$ Department of Medical Research \& Education, Taipei Medical University-Shuang Ho Hospital, New Taipei City 235, Taiwan. ${ }^{3}$ Department of Hematology and Oncology, Taipei Medical University-Shuang Ho Hospital, New Taipei City 235, Taiwan. ${ }^{4}$ Department of Urology, Taipei Medical University-Shuang Ho Hospital, New Taipei City 235, Taiwan.

Received: 8 December 2020 Accepted: 23 February 2021

Published online: 14 June 2021

\section{References}

1. Gallup JL, Sachs JD, Mellinger AD. Geography and economic development. Int Reg Sci Rev. 1999;22(2):179-232.

2. Easterly W, Levine R. Tropics, germs, and crops: how endowments influence economic development. J Monet Econ. 2003;50(1):3-39.

3. Braveman PA. Epidemiology and (neo-) colonialism. J Epidemiol Community Health. 2001;55(3):160-1.

4. Dudley L, Montmarquette C. A model of the supply of bilateral foreign aid. Am Econ Rev. 1976;66(1):132-42.

5. Crowards T. Defining the category of 'small' states. J Int Dev. 2002;14(2):143-79.

6. Jalan B. Problems and policies in small countries. London: Croom Helm; 1982.

7. Downes AS. On the statistical measurement of smallness: a principal component measure of country size. Soc Econ Stud. 1988;37:75-96.

8. Schiavo-Campo S. Some considerations on development aid to small countries. In: Selwyn P, editor. Development Policy in Small States. London: Croom Helm; 1975. p. 164-84.

9. Prussing E. Critical epidemiology in action: research for and by indigenous peoples. SSM-Popul Health. 2018;6:98-106.

10. Sachs J, Malaney P. The economic and social burden of malaria. Nature. 2002;415(6872):680.

11. World Health Organization. Action and investment to defeat malaria 2016-2030_for a malaria-free world. Technical report. Geneva: WHO; 2016.

12. Okorosobo T, Okorosobo F, Mwabu G, Orem JN, Kirigia JM. Economic burden of malaria in six countries of Africa. Eur J Bus Manag. 2011;3(6):42-63.

13. Tarnoff C. US Agency for International Development (USAID): background, operations, and issues. Washington DC: Congressional Research Service; 2015

14. Williams HA, Durrheim D, Shretta R. The process of changing national malaria treatment policy: lessons from country-level studies. Health Policy Plan. 2004;19(6):356-70.

15. International Organization for Standardization. ISO. https://www.iso.org/ home.html. Accessed 15 Oct 2020.

16. Hagenlocher M, Castro MC. Mapping malaria risk and vulnerability in the United Republic of Tanzania: a spatial explicit model. Popul Health Metr. 2015;13(1):2

17. Sachs JD, Warner A, Åslund A, Fischer S. Economic reform and the process of global integration. Brook Pap Econ Act. 1995;1995(1):1-118.

18. Knack S, Keefer P. Institutions and economic performance: crosscountry tests using alternative institutional measures. Econ Polit. 1995;7(3):207-27.

19. Sagar AD, Najam A. The human development index: a critical review 1. Ecol Econ. 1998;25(3):249-64.

20. Global Malaria Programme WHO. Policy brief for the implementation of intermittent preventive treatment of malaria in pregnancy using sulfadoxine-pyrimethamine (IPTp-SP). Geneva:WHO; 2013. https://www. who.int/malaria/publications/atoz/policy_brief_iptp_sp_policy_recom mendation/en/. Accessed 15 Nov 2020. 
21. Ekström J. The phi-coefficient, the tetrachoric correlation coefficient, and the Pearson-Yule debate. 2011. https://escholarship.org/uc/item/7qp46 04r. Accessed 12 Nov 2020.

22. Yeomans KA, Golder PA. The Guttman-Kaiser criterion as a predictor of the number of common factors. The Statistician. 1982;31:221-9.

23. Liang L-L, Mirelman AJ. Why do some countries spend more for health? An assessment of sociopolitical determinants and international aid for government health expenditures. Soc Sci Med. 2014;114:161-8.

24. Hay SI, Guerra CA, Tatem AJ, Noor AM, Snow RW. The global distribution and population at risk of malaria: past, present, and future. Lancet Infect Dis. 2004:4(6):327-36.
25. Gupta S, Davoodi H, Tiongson E. Corruption and the provision of health care and education services. In: Jain AK, editor. The Political Economy of Corruption. Abingdon-on-Thames: Routledge; 2001. p. 123-53.

26. Dave S, Dave P, Pal M. The impact of climate change on the emergence and re-emergence of vector borne human diseases. Int J Livest Res. 2015;5:1-10.

\section{Publisher's Note}

Springer Nature remains neutral with regard to jurisdictional claims in published maps and institutional affiliations.
Ready to submit your research? Choose BMC and benefit from:

- fast, convenient online submission

- thorough peer review by experienced researchers in your field

- rapid publication on acceptance

- support for research data, including large and complex data types

- gold Open Access which fosters wider collaboration and increased citations

- maximum visibility for your research: over $100 \mathrm{M}$ website views per year

At BMC, research is always in progress.

Learn more biomedcentral.com/submissions 